\title{
Itinerários do livro didático como objeto central no ensino de História
}

\author{
Itineraries of the textbook as the central object in the teaching \\ of History
}

\author{
Jeferson Rodrigo da Silva ${ }^{1}$
}

\section{RESUMO}

O livro didático é um objeto central nas práticas de ensino de História. Para além de abordar os problemas que podem vir junto com tal afirmação, este texto apresenta a trajetória histórica da centralidade do livro didático, entendido como totalidade, na história do ensino de História no Brasil. Por meio dos referenciais teóricos escolhidos, mostra-se como essa centralidade é complexa, assumindo contornos específicos nos diversos momentos apresentados. Referência pedagógica, orientador da prática docente, vilão das boas práticas de ensino, objeto cultural complexo ou conquista da população. Estas diferenças demonstram que, para entender o livro didático como um objeto central nas práticas de ensino, de modo complexo, é preciso considerar as variações epistemológicas das abordagens acadêmicas, as políticas públicas voltadas para a educação, as tecnologias e as demandas sociais e econômicas além das funções básicas que, historicamente, construíram este objeto como uma totalidade.

Palavras-chave: História e ensino. Livro didático. Utilização de livro didático. Centralidade. Objeto cultural complexo.

\section{ABSTRACT}

The textbook is a central object in the practice of teaching History. In addition to addressing the problems that can come along with this statement, this paper presents the historical trajectory of the centrality of the textbook, understood as a totality, in the history of History teaching in Brazil. Through the theoretical reference chosen, it is shown how this centrality is complex, assuming specific contours in the different moments presented. Pedagogical reference, supervisor of teaching practice, villain of good teaching practices, complex cultural object or conquest of the population. These differences demonstrate that, to understand the textbook as a central object in teaching practices, in complex way, it is necessary to consider the epistemological variations of the academic approaches, the public policies focusing on education, the technology and the economic and social demands besides the basic functions that 
historically built this object as a whole.

Keyword: History and teaching. Textbook. Use of textbook. Centrality. Complex cultural object.

\section{Introdução}

O livro didático de História é um objeto central nas práticas de ensino. Sustentar essa afirmação nos dias atuais implica, inevitavelmente, na formulação de uma questão fundamental: de qual centralidade e de qual livro didático estamos falando? Logo de início, afirmamos que a pergunta implica em abordarmos a complexidade inerente ao papel do livro didático nas práticas de ensino de História. Por isso, a velha imagem do professor, cuja formação precária restringiu sua atuação, em sala, aos limites de um livro didático, entendido como única alternativa para suas práticas e um ambiente com alunos indisciplinados, por conta da monotonia e repetição de uma leitura apática e pouco estimulante, não é a melhor representação daquilo que pretendemos discutir neste texto. Em outras palavras, afirmar a centralidade do livro didático não significa que ele domine as práticas de ensino.

O que significa pensarmos a questão de maneira complexa? Basicamente, entendemos que a centralidade do livro didático dialoga com a relação entre este objeto cultural e as práticas de utilização que possibilitam a produção de sentidos diversos nas aulas de História. Esta relação não é isenta de historicidade. Para tratarmos essa problemática, apresentaremos a fundamentação teórica e os aspectos que justificam a centralidade do ensino sobre este material, entendido como uma totalidade. Em seguida, mostraremos, por meio de diversas pesquisas, as transformações, pelas quais passou o livro didático como objeto central nas práticas de ensino, ao longo dos séculos XIX e XX. Nosso objetivo é mostrar a importância de tratarmos dessa centralidade como algo complexo.

\section{O ensino de História na modernidade e o livro didático como totalidade}

Recorrendo, brevemente, às pesquisas sobre a História da alfabetização no continente europeu, Hébrard mostra que, desde o surgimento, na França, dos primeiros projetos de ensino voltados para um público não ligado à Igreja, até sua massificação no século XIX, a preocupação de educar as pessoas por meio da leitura foi guiada, primeiramente, pelos preceitos religiosos e, posteriormente, pelos projetos da modernidade ligados ao Estado: 
Das reformas no século das Luzes até as expansões escolares do século XIX, cada política educativa estava plenamente convencida disto: o ensino da leitura é um meio de transformar os valores e os hábitos dos grupos sociais que são seu alvo. (HÉBRARD, 2002, p. 35).

Quando abordam a História da educação no Brasil, Bezerra, Luca (2009) e Bittencourt (2008) mostram que essa preocupação era evidente no processo de constituição da disciplina escolar História e na sua relação com os manuais escolares:

No Brasil, Estado e Igreja, afastando-se ou aproximando-se, produziram e efetivaram projetos educacionais variados no decorrer do século XIX e primeiro decênio do atual, provocando conflitos ou conciliando interesses que expressavam a contradição inerente da educação escolar proposta com base nas transformações econômicas e políticas configuradas pela revolução francesa. (BITTENCOURT, 2008, p. 23).

Considerando estas ideias, acreditamos que a escola como conhecemos constituiu-se como uma instituição moderna ${ }^{2}$ cuja característica de maior relevância consiste, por excelência, em ser a instituição formadora de nossos jovens. Segundo Sacristán (1995, p. 41), ela traduz-se como "[...] a oportunidade de impulsionar para adiante a humanidade e [...] uma ocasião para redimir as chagas sociais e os defeitos dos adultos [...]". Esse reconhecimento da escola, como instituição formadora, é compartilhada por Chevallard (1991, P. 13), quando diz que

Hoje, mais do que ontem, esse sistema deve suportar o peso das expectativas, os fantasmas, as exigências de toda uma sociedade para a qual a educação é a última reserva de sonhos que desejaríamos poder exigir em sua totalidade. (tradução nossa).

Não podemos negar que exista, nos dias atuais, uma esperança depositada nas instituições escolares no sentido de melhorar o futuro pela conscientização dos jovens. Por que ensinamos História para os nossos alunos nos dias atuais? Torná-los pessoas conscientes de seu papel na sociedade, atuar de forma crítica, são falas que ouvimos e lemos

2 Nosso entendimento de instituição moderna é influenciado pelos trabalhos de dois autores. Em seu livro, intitulado A sociedade industrializada: vidas contadas e histórias vividas, Bauman (2008) mostra a crise em que se encontra o modelo moderno de escola em nossos dias por conta da influência dos recursos midiáticos. Da mesma forma, no texto $O$ projeto educacional moderno: identidade terminal?, Silva (1995) apresenta uma definição clara da educação na modernidade para enfatizar sua crise e as possibilidades de se pensar a identidade educacional pelo enfoque pós-moderno e pelo que ele define como assalto neoliberal. 
incontáveis vezes pelos corredores de escolas, na mídia e em trabalhos acadêmicos desde que ocorreu o processo de redemocratização na década de 1980.

Ao pensarmos a escola e a disciplina escolar História neste contexto, qual seria o papel do livro didático? Enquanto prática moderna, a leitura deste material - mas não somente ele - corresponde à leitura de um conhecimento autorizado do qual a escapada é difícil. Ainda mais em situações onde "Aprender os saberes ensinados na escola equivale a ler os textos em que eles estão codificados. Estudar na escola é ler os livros didáticos e demais materiais escolares, em que a escritura predomina" (MUNAKATA, 2010, p. 225).

Se considerarmos a leitura como uma atividade fundamental para a formação dos alunos, não podemos ignorar a posição privilegiada ocupada pelo livro didático. Pela tradição e pela facilidade de acesso, este material é, na modernidade, controle sobre o escrito ou, em outras palavras, controle sobre os conteúdos a serem ensinados. Apesar da afirmação não ser propriamente um consenso, este objeto apresenta algumas características que permitem sustentar essa perspectiva pelo fato de ele prescrever conhecimentos históricos autorizados. De acordo com Munakata (2002, p. 90), na constituição da escola moderna, "[...] o livro necessariamente se faz presente, não como um acessório a mais, mas como um dispositivo fundamental".

É exatamente por esta importância que propomos a ideia de pensá-lo como uma totalidade em que a relação entre o texto e a materialidade que lhe serve de suporte constituem algo pronto e acabado. Para fundamentar essa ideia, recorremos à Chartier e Hébrard (1998, p. 39, grifo nosso) ao afirmarem que "Escrever, produzir a totalidade como texto, mediante relatos, pesquisas, quadros, mapas, gráficos é o trabalho novo da modernidade em que se realiza essa marcha para frente que se chama Progresso".

Em nossa pesquisa, a definição de totalidade agrega três ideias fundamentais: primeiramente, a concepção de Certeau, referente à escrita como prática mítica moderna. Para este autor, a escrita "[...] estoca aquilo que vai selecionando e se dá os meios de uma expansão. Combinando o poder de acumular o passado e o de conformar a seus modelos a alteridade do universo, é capitalista e conquistadora" (CERTEAU, 2003, p. 226, grifos do autor). Esta ideia remete à escrita historiográfica na modernidade científica e permite considerarmos o livro didático como totalidade no momento em que o entendemos como a escrita de uma História escolar. Ser capitalista e conquistadora corresponde à ideia de armazenar, conformar e tornar explicáveis os conhecimentos históricos por meio do produto dessa escrita.

A segunda ideia corresponde à ordem dos livros, apresentada por Chartier. Para este autor: 
o livro sempre visou instaurar uma ordem; fosse a ordem de sua decifração, a ordem no interior da qual ele deve ser compreendido ou, ainda, a ordem desejada pela autoridade que o encomendou ou permitiu a sua publicação. [...]

A ordem dos livros tem também um outro sentido. Manuscritos ou impressos, os livros são objetos cujas formas comandam, se não a imposição de um sentido ao texto que carregam, ao menos os usos de que podem ser investidos e as apropriações às quais são suscetíveis. (CHARTIER, 1994, p. 8).

A materialidade do livro, e para nós a do livro didático, constitui-se como totalidade a partir da relação entre os procedimentos de produção de texto e os procedimentos de produção do livro, os protocolos de leitura (CHARTIER, 1998). As implicações destes protocolos são evidenciadas em outra publicação do autor:

Sabemos que o códex, manuscrito ou impresso, permitiu gestos inéditos (folhear o livro, citar trechos com precisão, estabelecer índices) e favoreceu uma leitura fragmentada mas que sempre percebia a totalidade da obra, identificada por sua própria materialidade. (CHARTIER, 2002, p. 30).

A evidência básica dessa totalidade é a tentativa de protocolar uma leitura autorizada e os elementos básicos do livro didático que permitem essa ideia são, entre outros, a linearidade do texto e a figura do autor como parte importante da identidade da obra.

A terceira ideia diz respeito às funções básicas atribuídas a este material. Choppin mostra que, historicamente, o livro didático apresenta quatro funções cujas particularidades dependem do ambiente sociocultural, da época, dos níveis de ensino e dos métodos e formas de utilização deste material. São elas: a) tunção referencial, ele constitui o suporte privilegiado dos conteúdos educativos e referência daquilo que determinados grupos sociais acreditam ser necessário transmitir para as gerações futuras; considerando essa funcionalidade, o livro está intimamente ligado com os programas curriculares; b) função instrumental, ele propõe atividades que visam efetivar a aprendizagem de conteúdos e/ou habilidades; c) função ideológica, considerada a função mais antiga do livro didático que, desde o século XIX, foi constituído com o objetivo de disseminar determinadas ideologias e culturas autorizadas; d) função documental, o livro contém diversos documentos que, confrontados com outros documentos, possibilitam o desenvolvimento do senso crítico nos alunos (CHOPPIN, 2004). Entendemos que estas funções básicas são características do livro didático pensado como totalidade. ${ }^{3}$

3 Baldissera (1993) oferece um exemplo fundamental do entendimento do livro didático como uma totalidade ao demonstrar três aspectos que, em seu entendimento, dificultam a aprendizagem significativa por parte dos alunos: a 
Em síntese, ao considerarmos a escrita como prática mítica moderna, a ordem dos livros e as funções básicas deste material, nós conseguimos compreender como o livro didático tornou-se tão importante nos dias atuais:

Se, portanto, a escola é o "lugar de aprendizagem de formas de exercício do poder" impessoal, isso é possibilitado por uma organização de transmissão cultural baseada no escrito, tomado como autoridade, da qual os professores não passam de representação intercambiável. $\mathrm{O}$ escrito, em particular o livro didático, estabelece no seu uso uma relação hierárquica de poder, fundada na autoridade que dele emana. (MUNAKATA, 2010, p. 230).

A perspectiva de Certeau, no que se refere à dimensão do crível, ajuda a entendermos a afirmação anterior. Para ele:

Esse enfoque da atualidade pode distinguir aí os dois dispositivos pelos quais uma dogmática sempre se impôs á crença: de um lado, a pretensão de falar em nome de um real que, supostamente inacessível, é ao mesmo tempo o princípio do ato de crer (uma coisa sempre subtraída, inverificável, ausente); de outro lado, a capacidade do discurso, autorizado por um "real" para se distribuir em elementos organizadores de práticas, isto é, em "artigos de fé". Essas duas forças tradicionais se acham hoje no sistema que combina com a narratividade da mídia - uma instituição do real - o discurso dos produtos de consumo - uma distribuição deste real em "artigos" que se devem crer e comprar. (CERTEAU, 2003, p. 286, grifos do autor).

Para entendermos o livro didático como totalidade, é importante considerá-lo um artigo de fé, capaz de falar em nome de um real. Esta perspectiva, inclusive, ajuda a compreendermos porque, em diversas situações, os conhecimentos presentes neste material foram ou são tomados como verdade pronta e acabada. Considerando o livro didático de História, como essa ideia se constituiu historicamente? Quais as especificidades dessa representação ao longo da História do ensino de História no Brasil?

existência de uma História com base conceitual anacrônica; o fato de as seleções serem resultantes da personalidade, da ideologia, da cultura e do juízo de valor dos autores; e as generalizações construídas a partir de eventos específicos. Para Fonseca (2007, p. 52-53), um dos elementos fundamentais do livro didático, pensado como totalidade, consiste no processo de simplificação do conhecimento histórico que é responsável pelas seleções, pela defesa de uma determinada perspectiva de História e pela exclusão de determinados assuntos. 


\section{O século XIX, a constituição do livro didático e da História como disciplina escolar}

Vimos que, na marcha para o Progresso, é necessária uma formação de qualidade para os nossos jovens. Assim era a ideia predominante em parte do século XIX e boa parte do XX. O papel fundamental dos manuais escolares esteve efetivamente ligado à busca desse objetivo. Em sua constituição, a partir do século XIX, este tipo de material agregou funções que definiram seu papel central nas práticas de ensino mantendo-se, de certa maneira, até os dias atuais. Ao situar os manuais escolares como documentos históricos, as falas de Choppin (2007) são indicativas das funções básicas que este material adquiriu em determinados momentos históricos. Segundo autor, os manuais se inscrevem sobre a realidade material e participam do universo cultural, além de se destacarem como a bandeira ou a moeda no que se refere à sua importância simbólica. Eles têm "[...] por regra, primeiramente, transmitir aos jovens os saberes; o saber-fazer cuja aquisição é considerada indispensável para a perpetuação da sociedade, conforme um determinado grupo em determinado momento" (CHOPPIN, 2007: p. 4, tradução nossa).

Com o objetivo de compreender a constituição da disciplina escolar História e, consequentemente, a dos manuais escolares, Bittencourt mostra que a preocupação com o escrito esteve presente nos projetos educacionais constituídos ao longo do XIX, fossem aqueles realizados nos primeiros anos após a constituição de 1824 ou depois da criação do IHGB e do colégio D. Pedro II. "A obra didática era concebida como principal instrumento para divulgação do ideário educacional, dependendo dela, a formação do professor e do aluno" (BITTENCOURT, 2008, p. 26).

Com essa evidência, percebemos a importante relação constituída entre o Estado ${ }^{4}$, os autores, editores e os leitores desse tipo de material - o professor e os alunos - que o tinham como referência para os estudos. De acordo com Luca,

[...] o Estado desempenha papel essencial, pois é da sua competência definir os contornos do aparato escolar, sobre o qual tem o poder de legislar, formular propostas pedagógicas, impor conteúdos, programas curriculares e normas para os profissionais que neles atuam. (LUCA, 2009, p. 153).

Esta relação, fundamental para compreendermos a centralidade das práticas de ensino em relação ao livro didático, explica-se pelo fato de os livros serem potencialmente capazes de induzir novos hábitos, pelo menos na visão daqueles que detinham certo controle sobre

4 Ao pensarmos a relação entre as elites detentoras de poder e sua relação com o livro didático, Bezerra e Luca (2006) afirmam que a relação entre eles, até as primeiras décadas do século XX, era tênue e pouco definida. 
as políticas educacionais. Para "[...] os intelectuais que se dedicavam aos projetos educacionais, o livro escolar deveria condicionar o leitor, refrear possíveis liberdades diante da palavra escrita, impressa" (BITTENCOURT, 2008, p. 27).

\section{Livro didático e identidade nacional}

Entre os séculos XIX e XX, os livros didáticos constituíram-se como ferramentas necessárias para a formação da unidade nacional no Brasil. Projeto que, segundo Fonseca, tornou-se mais estruturado a partir das reformas no sistema de ensino ocorridas nas décadas de 1930 e 1940. Deste momento em diante, "[...] não mais deixaram de haver programas curriculares estruturados, com definição de conteúdos, indicação de prioridades, orientação quanto aos procedimentos didáticos e indicação de livros e manuais" (FONSECA, 2004, p. 52).

Um dos acontecimentos mais significativos do período, segundo Bezerra e Luca (2006, p. 29), foi a criação do MES. O Ministério de Educação e Saúde pode ser considerado “[...] um marco inicial para a fase de ações concretas em relação à produção, compra e distribuição de livros didáticos". Tais ações adquiriram contornos mais nítidos na década de 1930.

O controle sobre o livro permitiu que se configurasse uma "época de ouro" da centralidade sobre este material durante boa parte do século XX (FREITAS, 2009). Entre 1910 e 1960

[...] depositou-se no artefato uma grande responsabilidade no sucesso e na qualidade dos ensinos primário e secundário. As iniciativas do Estado em normatizar a produção, circulação e usos com Sampaio Dória (1917) em São Paulo, Gustavo Capanema - CNLD (1938) e Anísio Teixeira - INEP (1952) no Distrito Federal, da Comissão do Livro Técnico e do Livro Didático - COLTED (1966), são indícios de que o livro didático era também um componente estratégico para a renovação das práticas escolares. (FREITAS, 2009, p. 15).

Com estes indícios, entendemos que a centralidade sobre o livro didático, totalidade constituída pelo controle sobre o escrito, consolidou sua função como instrumento de suma importância para um ensino de História a favor do projeto nacional.

Remetendo-nos à década de 1970, em plena ditadura, é possível constatar importância semelhante. Considerando o ensino de História, Monteiro (2009, p. 181) afirma que "No caso do estudo da história, uma versão 'oficial', legitimadora do regime político e dos governos autoritários então no poder, com forte caráter doutrinário, estava embutida nas novas 
disciplinas criadas" e, consequentemente, nos manuais didáticos que, assim como outros canais de informação, operavam "[...] com eficiência no sentido de dizer quem esteve lá na 'Independência do Brasil', na 'revolução de 30' e assim por diante” (FONSECA, 1993, p. 142).

\section{Livro didático: um vilão necessário}

Ao dizermos que, do século XIX até a década de 1970, o livro didático deteve o estatuto de objeto essencial para os projetos educacionais, precisamos enfatizar dois aspectos para compreendermos a mudança de perspectiva ocorrida, no período, em relação a este material: primeiramente, até 1970, o livro didático era central nas práticas em sala de aula porque funcionava como referência pedagógica; com a massificação do ensino e a constituição das licenciaturas curtas no período da ditadura, o papel do livro passou a ser o de orientador e condutor da ação docente (BATISTA, 2002; GATTI JÚNIOR, 2004; BEZERRA; LUCA, 2006). Mais do que qualquer outro momento, este objeto cultural mostrava-se necessário para a efetivação do ensino, mas de uma forma peculiar, pois:

[...] o livro didático brasileiro se converteu numa das poucas formas de documentação e consulta empregadas por professores e alunos. Tornou-se, sobretudo, um dos principais fatores que influenciam o trabalho pedagógico, determinando sua finalidade, definindo o currículo, cristalizando abordagens metodológicas e quadros conceituais, organizando, enfim, o cotidiano da sala de aula. (BATISTA, 2001, p. 12).

Em nosso entendimento, a reconfiguração dessa centralidade constituiu-se de forma integradora ${ }^{5}$ por conta do descrédito que o livro didático passou a ter para diversos professores e pesquisadores. Os livros eram necessários e, ao mesmo tempo, vilões das boas práticas de ensino. Freitas (2009, p. 15) justifica a postura crítica, em relação a este material, pelas formas de ensino pautadas no construtivismo que ganharam visibilidade no período: "Variantes do construtivismo negam a possibilidade de a construção do conhecimento, por parte do aluno, basear-se num livro escolar na sua forma tradicional". O autor complementa essa justificativa considerando, também, a publicação de inúmeras análises críticas de conteúdo de caráter ideológico, em sua maioria, lançadas na década de 1980 cuja

5 Para Vasconcellos (2002, p. 113-114), o pensamento integrador considera os elementos ou indivíduos da análise de maneira articulada, porém sem que haja determinação, reduções ou eliminação das diferenças. Este pensamento articula-se com o princípio dialógico definido por Morin. "[...] esse princípio significa articular, mantendo a dualidade no seio da unidade, sem pretender realizar uma síntese, como acontece na dialética”. 
finalidade era denunciar as ideologias dominantes subjacentes aos textos didáticos. Este contexto permitiu que os livros didáticos fossem desacreditados.

O papel atribuído ao livro didático pelas novas perspectivas e pelas denúncias apresentadas em diversos trabalhos, tiveram como resultado a postura de aversão a este tipo de material a partir da década de 1980, pois os livros didáticos

[...] passaram a ser considerados "vilões" da educação, portadores de ideologias indutoras de processos de reprodução das desigualdades e hierarquias sociais, em textos conservadores, "oficiais", muitas vezes repletos de erros ou em versões ultrapassadas pelas pesquisas cientificas. (MONTEIRO, 2009, p. 181).

Se até este momento pudemos perceber, com contornos nítidos, a centralidade do livro didático fundamentada pelos projetos governamentais - argumento agora utilizado para dizer que estes materiais traziam uma concepção "tradicional" de História - as mudanças substanciais ocorridas com a redemocratização do Brasil deixaram as bases sólidas do livro didático, como objeto central do ensino, drasticamente abaladas.

Considerando essa mudança, podemos dizer que as novas propostas curriculares e a valorização do saber histórico escolar como produção de conhecimento em sala de aula (FONSECA, 1993) alteraram o papel exercido pelo livro didático em sala? A problemática constituição do PNLD em 1985 (MUNAKATA, 1997) e sua consequente debilidade nos processos de escolha e distribuição facilitaram a diminuição da centralidade neste objeto? $\mathrm{O}$ crescimento das publicações paradidáticas e o incentivo para a utilização de recursos variados na sala de aula serviriam de respostas para essa diminuição?

Como ressalta Fonseca (1993, p. 133), o ensino de História agregou outros recursos derivados dos meios de comunicação como os paradidáticos, jornais, revistas, programas de TV, filmes, entre outros que passaram a dividir espaço com o livro didático dentro e fora da sala de aula.

Para Bittencourt (1996, p. 94), os livros didáticos passaram a ter "[...] como concorrentes os meios de comunicação de massa, o cinema, a televisão e seu mundo de imagens". Disputando ou dividindo espaços, podemos dizer que esses materiais tiraram a centralidade do livro didático? Ou as transformações que permitiram uma centralidade integradora do livro não se configurariam elas mesmas menos em medidas inovadoras para as práticas de ensino de História do que na tomada de consciência da totalidade em relação ao objeto livro didático (VILLALTA, 2001, p. 48) e nas tentativas de "burlar" as funções básicas tradicionalmente atribuídas a este material? 
Nesta perspectiva de análise, é possível compreendermos os resultados das primeiras pesquisas que se dedicaram à compreensão dos usos do livro didático pelo professor e pelos alunos. Na década de 1980, ainda no calor das transformações anteriormente citadas, Freitag, Costa e Motta (1993, p. 108) mostram uma situação desalentadora, pois, de acordo com algumas pesquisas, "[...] fica evidente que o livro didático não serve aos professores como simples fio condutor de seus trabalhos, mas passa a assumir o caráter de "critério de verdade' e 'última palavra' sobre o assunto". No estado da arte apresentado pelas autoras, os indícios dessa constatação estendem-se para outras pesquisas apresentadas naquela publicação.

Mesmo tratando de livros de outras disciplinas, Pondé, Alves e Rollin (1984) demonstram, em um estudo com professores da cidade do Rio de Janeiro, sentimento de surpresa ao constatar que aqueles profissionais utilizavam livros péssimos - de acordo com análises críticas de conteúdo do período - afirmando serem bons. A centralidade do livro didático, evidenciada no trabalho das autoras, foi atribuída à acomodação, porém, havia também professores que demonstravam resistência em relação aos materiais desacreditados pela academia. Mesmo percebendo que os professores de $5^{\mathrm{a}}$ à $8^{\mathrm{a}}$ série faziam melhor seleção do livro em relação aos professores de $1^{\mathrm{a}}$ á $4^{\mathrm{a}}$ série, as conclusões do trabalho mostram que "[...] o livro didático mais adotado é qualitativamente muito inferior aos que lhe seguem, porque propõe uma metodologia centrada na mecanização de conceitos e não propicia ao aluno manifestações mais livres de suas idéias" (PONDÉ; ALVES; ROLLIN, 1984, p. 32, grifo nosso).

A questão final do artigo consiste em perguntar por que os professores pesquisados escolheram livros tão ruins e as respostas demonstraram problemas na qualidade dos cursos de graduação em instituições particulares e nos próprios livros que traziam, sobre o rótulo de novidade, os mesmos textos e exercícios exaustivamente criticados por diversos pesquisadores como tradicionais.

De acordo com Freitag, Costa e Motta (1993, p. 111), alguns trabalhos, como o exemplo apresentado anteriormente, demonstram que "O livro didático não funciona em sala de aula como um instrumento auxiliar para conduzir o processo de ensino e transmissão do conhecimento, mas como o modelo-padrão, a autoridade absoluta, o critério último de verdade" (grifo nosso).

As mudanças de perspectiva acadêmica em relação ao livro didático, na década de 1980, mostram os problemas relacionados à utilização deste material como objeto central nas aulas. Os olhares mais atentos para a formação do professor se devem a isso. Em outras palavras, a tomada de consciência de que o livro didático persistiu como objeto central propicia questões a respeito da qualidade dos manuais escolares produzidos e utilizados, bem como da necessidade de investimentos em formação continuada - naquele momento 
denominada curso de reciclagem - para enfim os professores se libertarem do livro como controle sobre o escrito e material central no andamento das disciplinas.

\section{Livro didático como objeto central: tomada de consciência}

Essas falas intensificam-se ao longo da década de 1990. Mesmo relacionados a outros materiais nas práticas de ensino, alguns pesquisadores percebem que os livros didáticos mantêm sua importância como objeto central no ensino de História. Eles passam "[...] a ser cada vez mais reconhecidos e indicados, nas políticas educacionais, como documentos de importância estratégica [...] na educação básica dos países em desenvolvimento" (MONTEIRO, 2009, p. 179) demonstrando, segundo a pesquisadora, serem mais efetivos que propostas curriculares inovadoras.

Encontramos um exemplo desta constatação no texto de Villalta que, após ressaltar as discussões acadêmicas que, naquele momento, buscavam o ensino de História como um trabalho - termo utilizado para se referir à produção de conhecimento histórico escolar -, o autor percebe que, na prática, é possível categorizar dois modelos de aula:

[...] o da aula-livro didático ou o dos cursos magistrais-livro didático, em algumas situações copiando da lousa, ao que se segue uma breve explicação que não vai além do que existe no livro e, depois, a resolução pelos alunos dos famigerados questionários ou de exercícios imbecilizantes (exemplos: "cruzadinha histórica", "complete as lacunas", "associe a coluna da esquerda com a da direita" etc.), posteriormente corrigidos em sala de aula e, então... tudo começa outra vez.

[...]

Em ambos os casos, pode-se constatar a importância assumida pelo livro didático, seja porque se converte na aula, na primeira situação, seja porque se apresenta, no segundo modelo, como um complemento fundamental para o aluno, na medida em que o ajuda a "achar-se" em meio à longa explanação do professor. (VILLALTA, 1994, p. 41, grifos do autor).

Na busca por um ensino de qualidade, em que a valorização dos alunos como sujeitos históricos é essencial, sua tomada de consciência sobre a centralidade do livro didático deixa latente certa frustração em relação ao público majoritário de professores com formação precária e com determinadas produções que ele denomina "lixo" didático (VILLALTA, 1994, p. 42). 
Considerando o período entre as décadas de 1970 e 1990, Gatti Júnior mostra fortes indícios de que o livro como elemento central, nas aulas de História, também é uma justificativa para sua pesquisa, desenvolvida em um período marcado por debates intensos sobre a qualidade dos livros didáticos distribuídos pelo PNLD. ${ }^{6}$ Para ele, os livros didáticos "[...] assumiram um papel duplo: o de portadores dos conteúdos disciplinares e de organizadores das aulas" (GATTI JÚNIOR, 2004, p. 29).

Percebemos algumas diferenças entre a centralidade do livro didático criticada no decorrer da década de 1980 e a forma como é apresentada em algumas pesquisas na década seguinte. No primeiro caso, a totalidade é compreendida por meio da postura crítica frente à tradição que os livros didáticos construíram, ao longo do século XIX e XX, como material central para a disseminação de uma concepção de História específica. Mesmo buscando saídas para um desprendimento desse material, algumas pesquisas do período mostraram que os professores, profissionais pouco informados segundo os pesquisadores, não deixam de usar esse material de modo "equivocado". No segundo caso, a totalidade apresenta-se pelas seleções de conteúdos realizadas para a História enquanto disciplina escolar. Neste contexto, o livro didático tornou-se objeto central no ensino porque materializa os objetivos da História como uma disciplina.

Uma das marcas do período consiste em certo tom de lamento pelos livros didáticos continuarem centrais no ensino, mesmo em um contexto de intensos debates sobre a utilização de outros materiais nas práticas de ensino de História. Munakata demonstra esse aspecto ao falar da constituição de livros didáticos em meio às propostas curriculares para a disciplina História no início da década de 1990. Período onde:

[...] o que acabou prevalecendo como currículo de História no vazio da iniciativa do governo é esse conteúdo consensual dos livros didáticos, complementado pelos paradidáticos. E na medida em que as editoras paulistas têm praticamente o monopólio do mercado de livros didáticos de todo o país (inclusive de edições regionais), não é exagero supor que tal "currículo" informal tenha alcançado abrangência nacional. (MUNAKATA, 2003, p. 296).

Por este motivo, entendemos porque Bittencourt reconhece que os livros didáticos continuam sendo "[...] referencial dos professores, pais e alunos que, apesar do apreço, consideram-no referencial básico para o estudo [...]" (BITTENCOURT, 1998, p. 71).

Nesse momento, passa-se a falar, de forma intensa, sobre a qualidade do livro didático por conta, principalmente, das iniciativas governamentais de avaliar os livros distribuídos

6 Apesar de ter sido publicado em 2004, este trabalho remete diretamente à tese do autor, defendida no ano de 1998. 
nas escolas públicas. No contexto em que são mostrados diversos problemas relacionados a esse objeto, a centralidade era algo preocupante:

Sua importância aumenta ainda mais em países como o Brasil, onde uma precaríssima situação educacional faz com que ele acabe determinando conteúdos e condicionando estratégias de ensino, marcando, pois, de forma decisiva, o que se ensina e como se ensina o que se ensina. (LAJOLO, 1996, p. 4).

Para Caimi (1999, p. 26), esta constatação é relevante porque os professores estabeleceram relações com o livro didático que não o tomam como meio auxiliar do processo de ensino de aprendizagem, mas sim como recurso único e absoluto. Da mesma forma, Fonseca (2007, p. 49) fala posteriormente que "[...] ele constitui a principal fonte de estudo, o elemento predominante e muitas vezes determinante no processo de ensino".

De acordo com Munakata, esta centralidade, enfatizada pelas pesquisadoras, está atrelada ao investimento do Banco Mundial que prioriza o desenvolvimento e a melhoria dos livros didáticos bem mais do que a formação docente:

[...] os professores são também suspeitos de não terem tido formação adequada. Os programas de capacitação, por outro lado, são considerados muito onerosos em relação aos resultados, pois há sempre o risco de o professor abandonar a carreira uma vez concluído o processo de sua qualificação. $O$ Banco Mundial também insiste em que a melhora do salário docente não acarreta por si só o rendimento escolar.

Numa política formulada a partir de tamanha desconfiança em relação ao professor, o livro didático obviamente assume a centralidade. (MUNAKATA, 2007, p.139, grifo nosso).

O autor percebe que a importância dada ao livro didático pelo Banco Mundial diferencia-se da forma como ele é apresentado nas avaliações do PNLD onde se mostra, pelo menos desde a edição de 2002, como instrumento auxiliar das práticas de ensino. "O que se postula, então, é não a contraposição entre o professor e o livro didático, e sim, ao contrário, a escolha, pelo professor bem informado, de livros adequados às diferentes necessidades e expectativas" (MUNAKATA, 2003, p. 141).

\section{Livro didático: um objeto cultural complexo}


Encontramos indícios dessa mudança, que explicam a transição de uma concepção de livro didático como muleta para a de auxiliar das práticas de ensino, no documento organizado por Batista (2001). Isso se deve à proposta do texto em avaliar os processos de avaliação do programa realizados até o momento:

[...] os editais do PNLD e seus critérios de avaliação mostram que o Programa é tributário deste modelo cristalizado de manual escolar, já que é essa concepção de livro didático que o PNLD pressupõe; pressupondo-a, tende a contribuir para sua permanência, inibindo o surgimento de outros padrões de manuais escolares e limitando, assim, sua participação na promoção da melhoria da qualidade do ensino. (BATISTA, 2001, p. 30).

As recomendações para a superação dessa concepção são bastante enfáticas na importância de uma mudança de posturas que envolvessem a acolhida de propostas inovadoras no que se refere às relações entre manuais didáticos e professores, a renovação dos padrões editoriais associados à ideia de livro didático, tradicionalmente enraizada na sociedade brasileira e, consequentemente, a abertura do conceito livro didático a fim de ampliar e diversificar a oferta de materiais inscritos (BATISTA, 2001, p. 31).

O contexto de questionamentos sobre o livro didático permite compreendermos, por exemplo, os esforços de Munakata em ressaltar, de maneira contrária àqueles que consideram o livro didático uma muleta e símbolo de desqualificação do professor, que "[...] o professor carregando livro não é imagem estereotipada da sua deficiência a ser compensada com muleta, mas a afirmação da sua distinção profissional" (MUNAKATA, 2002, p. 91).

Outros trabalhos também apontam para a configuração dessa importância. Realizando uma radiografia das coleções didáticas da disciplina História, aprovadas no PNLD de 2005, Miranda e Luca utilizam-se de Sacristán (1995) para ressaltar a permanência do livro didático como objeto central, mesmo considerando a inserção efetiva de outros materiais para a prática de ensino de História, mas com algumas diferenças:

Os livros didáticos de História se apresentam, até pelo seu enorme grau de difusão, potencializado pela distribuição gratuita aos estudantes de escola pública de todo o país, como uma das mais importantes formas de currículo semi-elaborado, que nasce a partir de distintas visões e recortes acerca da cultura. Carregam consigo, portanto, múltiplas possibilidades de organização dessa relação entre o que é, o que pode ser e o que deveria ser aprendido em relação à disciplina. (MIRANDA; LUCA, 2004, p. 134). 
Segundo as autoras, a reafirmação do livro como ferramenta central para as práticas de ensino consolida-se, no século XXI, em um contexto de políticas públicas que procuram, cada vez mais, referir-se ao livro didático como material auxiliar. Percebemos que esta perspectiva, presente nos guias dos últimos PNLDs, não permite afirmarmos que a centralidade sobre este objeto tenha se equiparado aos outros recursos utilizados no ensino da disciplina. Em um trabalho mais recente, cujo objetivo é compreender, no estado de Sergipe, os usos dos Guias do livro didático de História do PNLD, publicados nos anos de 2005 e 2007, nas suas relações com a escolha das coleções didáticas pelos professores, Freitas et al. (2007, p. 56) chegam à conclusão de que "Independentemente de serem bons ou ruins, os livros didáticos são vistos como recursos básicos para o dia a dia do professor". Por meio da aplicação de entrevistas com sessenta professores daquele estado, a conclusão sobre a centralidade do livro didático foi a de que os "[...] manuais permanecem como o principal recurso, além da voz do mestre. Vimos como foi expressiva a quantidade dos professores que entenderam o Livro Didático como o ditador da sequência didática" (FREITAS et al., 2007, p. 57, grifo nosso).

Com as conclusões apresentadas, sustentamos que a centralidade do trabalho docente no livro didático mantém-se, mas de forma integradora. Reconhecê-lo como um objeto cultural complexo permite entendermos essa centralidade pautada pelo princípio dialógico entre o livro didático como uma totalidade e o professor e seus alunos como usuários. Não se trata, propriamente, de reivindicar papeis mais ou menos determinantes das práticas a este suporte. Nossa tomada de consciência consiste em pensarmos como acontece essa relação.

Os resultados apresentados por Monteiro, a respeito de uma pesquisa sobre a utilização de livros didáticos no ensino médio em escolas do Rio de Janeiro entre 2005 e 2006, são sintomáticos desta perspectiva:

[...] os professores entrevistados afirmaram utilizar os livros didáticos nas aulas como base para o estudo pelos alunos e para consulta. [...] o livro didático está inserido e subordinado à lógica e à organização didática do professor. (MONTEIRO, 2009, p. 197)

Considerando o tipo de utilização, poderíamos dizer que há uma redução na centralidade sobre do livro didático em sala? Tomamos um depoimento de empréstimo para ajudar nesta questão:

Livro didático é fundamental como consulta. E também de resumo de conteúdos. Dar aulas sobre o Primeiro Reinado, Revolução espanhola, Independência, Revolução Francesa é impossível sem o uso do livro 


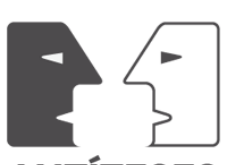

ANTÍTESES

didático. Uso o livro para passar em revista tudo isso. (MONTEIRO, 2009, p. 197, grifo nosso).

Como é apresentada pela autora, esta fala demonstra uma utilização que não se assemelha àquela utilização mecânica tão criticada entre as décadas de 1980 e 1990, porém, o tipo de uso reafirma a totalidade do livro em sala de aula. Este aspecto está presente na impossibilidade de trabalhar determinados conteúdos sem o uso deste material.

Notamos a relação complexa da centralidade do livro também na pesquisa de Coelho (2009) sobre os usos que professoras - da $4^{\mathrm{a}}$ série ( $5^{\circ}$ ano) do ensino fundamental de escolas de Betim-MG, no ano de 2006 - diziam fazer do livro didático História com Reflexão. As conclusões da autora são fundamentais para esta constatação:

As declarações das professoras indicam que, ao contrário do que se espera, esse livro distribuído pelo PNLD não é tomado como o principal referencial curricular das 12 professoras entrevistadas, embora exerça certa influência no processo de mudança de suas práticas docentes. [...] as professoras, pelo menos essas que lecionam para a $4^{\mathrm{a}}$ série $/ 5^{\circ}$ ano do Ensino Fundamental, em Betim, usam esse livro didático de História sob uma perspectiva diferenciada que inclui outro modo de conceber a aplicação e a recepção didática desse material. Nessa concepção, os livros didáticos, no plural, não necessariamente o de História, assumem o papel central nas práticas das professoras, ao ensinarem História. (COELHO, 2009, p. 301).

Essa pluralidade ressaltada pela autora refere-se à utilização de outros livros e materiais didáticos pelas professoras que participaram de sua pesquisa. Como no texto de Monteiro (2009), este trabalho indica uma diluição da centralidade como característica de seu aspecto integrador, algo que também constatamos nos resultados da pesquisa de Franco acerca da apropriação do livro Viver e aprender História, por quatro professoras da $4^{\mathrm{a}}$ série ( $5^{\circ}$ ano), na cidade de Uberlândia-MG, durante o ano de 2005.

No entanto, o maior ou menor uso do livro didático nas aulas não fez com que o enfoque dado por cada professora à história do município tivesse diferenças significativas. Isto é, mesmo selecionando diferentes partes do livro para trabalhar, criando caminhos e dinâmicas diferentes ao ler e desenvolver os textos e as atividades propostas no livro, para além das singularidades, a investigação da apropriação do livro Viver e aprender História por cada professora apontou aproximações entre elas. (FRANCO, 2009, p. 219-220, grifos do autor). 
As análises apresentadas demonstram a presença do livro como totalidade na dinâmica das professoras classificada, pela autora, como superposição entre uma perspectiva de ensino de História tradicional e outra inovadora (FRANCO, 2009). Dentre os diversos aspectos abordados, percebemos que, se as "[...] professoras e os textos por elas utilizados não contribuíram para a construção do pensamento histórico entre as crianças" (FRANCO, 2009, p. 222), isso se deve, em parte, à naturalização dos processos históricos, à ausência de conflitos e opressão sobre os pobres e sobre as minorias, e ao uso das fontes entendidas como memória de um passado:

\begin{abstract}
Mudanças que, de acordo com minhas investigações, conduzem-nos a relativizar a relação de dependência do professor com o livro, apesar da permanência da fragilidade da formação histórica, principalmente daqueles que atuam de $1^{\mathrm{a}}$ a $4^{\mathrm{a}}$ séries. A acusação de que as professoras utilizam o livro sem pensar nos valores e na ideologia que eles veiculam chocou-se com a observação de que, por exemplo, a Profa. Ana, ao trabalhar as idéias de caráter mais social sobre o MST presentes no livro didático, fez uma releitura conservadora dele para os alunos. Mesmo a Profa. Zilda que seguia muito as instruções do Livro do professor para encaminhar a explicação dos textos para seus alunos, não o fazia de forma tão submissa assim. (FRANCO, 2009, p. 229-230).
\end{abstract}

Timbó (2009) fornece um indício importante para dizermos que o lugar onde atuam os profissionais da educação relaciona-se, de maneira fundamental, com o reconhecimento, ou não, da centralidade do livro didático. Em sua pesquisa sobre a utilização de livros didáticos em quatro escolas de Fortaleza-CE e Quixadá-CE, durante os anos de 2007 e 2009, ela demonstra que

É inegável, porém, que o acesso a diferentes recursos didáticos já não seja algo tão distante em muitas escolas públicas, como nas quatro escolas onde fizemos a pesquisa empírica, pois estas são subsidiadas com televisão, DVDs, retroprojetor, sala de multimeios e laboratório de informática, contudo, o livro didático adotado em cada uma delas ocupa, segundo as entrevistas, um lugar de destaque no processo de ensino. (TIMBÓ, 2009, p. 61).

Durante suas análises, a autora constata a subutilização do livro didático, por uma das professoras que participou de sua pesquisa, com práticas que aproveitavam mal suas potencialidades. Apesar disso, essa subutilização não reduziu a importância deste material como objeto central (TIMBÓ, 2009, p. 156-157). 


\section{Considerações finais}

Para finalizarmos este texto, dois pontos precisam ser ressaltados: primeiramente, as transformações pelas quais passou a concepção do livro didático, como objeto central no ensino, são tributárias menos das efetivas práticas de leitura de professores e alunos ao longo das décadas do que das variações epistemológicas das abordagens acadêmicas, das políticas públicas voltadas para a educação, das tecnologias e das demandas sociais e econômicas, campos em constante tensão na busca por um ensino de História de qualidade.

Assim, podemos explicar as transformações do livro didático de um referencial pedagógico para um organizador das práticas docentes, vilão do ensino, que, nos dias atuais, é visto como uma conquista da população, pela maior qualidade e pelo acesso.

Segundo, não podemos esquecer que o livro didático como objeto central no ensino implica no reconhecimento desse material como uma totalidade em que determinadas funções (CHOPPIN, 2004, 2007) estão agregadas. Assim, mais do que criticar uma visão limitada e/ou enviesada dos conteúdos, é importante nos questionarmos sobre o porquê dessa constatação. Mesmo com os problemas que um uso intenso e exclusivo do livro didático pode trazer para as práticas de ensino de História, não podemos esquecer que este material é central. Mas esta é uma constatação em que o enfrentamento pode não ser a melhor saída.

\section{Referências}

BALDISSERA, José Alberto. O livro didático de História: uma visão crítica. São Leopoldo: Cultural, 1993.

BATISTA, Antonio Augusto Gomes. Recomendações para uma política pública de livros didáticos. Brasília: MEC/SEF, 2001.

. Um objeto variável e instável: textos, impressos e livros didáticos. In: ABREU, Márcia (Org.). Leitura, história e história da leitura. Campinas: Mercado das Letras; São Paulo: FAPESP, 2002. p. 529-575.

BAUMAN, Zygmunt. A sociedade individualizada: vidas contadas e histórias vividas. Rio de Janeiro: Jorge Zahar, 2008. 
BEZERRA, Holien Gonçalves; LUCA, Tânia Regina de. Em busca da qualidade PNLD História - 1996-2004. In: SPOSITO, Maria Encarnação Beltrão (Org.). Livros didáticos de história e geografia: avaliação e pesquisa. São Paulo: Cultura Acadêmica, 2006. p. 27-53.

BITTENCOURT, Circe. Práticas de leitura em livros didáticos. Revista da Faculdade de Educação, São Paulo, v. 22, n. 1, p. 89-110, jan./jun. 1996.

_ _ _ _ . Livros didáticos entre textos e imagens. In: BITTENCOURT, Circe (Org.). O saber histórico na sala de aula. São Paulo: Contexto, 1998. p. 69-90.

. Livro didático e saber escolar (1810-1910). São Paulo: Autêntica, 2008.

CAIMI, Flávia Heloisa. O livro didático: algumas questões. In: DIEHL, Astor Antônio. O livro didático e o currículo de história em transição. Passo Fundo: EDIUPF, 1999. p. 25-109.

CERTEAU, Michel de. A invenção do cotidiano: 1. artes de fazer. 9. ed. Petrópolis: Vozes, 2003.

CHARTIER, Anne-Marie; HÉBRARD, Jean. A invenção do cotidiano: uma leitura, usos. Projeto história, São Paulo, n. 17, p. 29-44, nov. 1998.

CHARTIER, Roger. A ordem dos livros. Brasília: UNB, 1994.

. Do livro à leitura. In: CHARTIER, Roger (Org.). Práticas de leitura. São Paulo: Estação Liberdade, 1998. p. 77-105.

. Os desafios da escrita. São Paulo: UNESP, 2002.

CHEVALLARD, Yves. La transposición didáctica: del saber sabio al saber enseñado. Buenos Aires: Aique Grupo, 1991.

CHOPPIN, Alain. História dos livros e das edições didáticas: sobre o estado da arte. Educação \& pesquisa, São Paulo, v. 30, n. 3, p. 549-566, set./dez. 2004.

_ _ _ _ _. Traiter le manuel scolaire comme source documentaire: une approche historique. Revista língua escrita, Belo Horizonte, n. 3, p. 1-10, dez. 2007.

COELHO, Araci Rodrigues. Usos do livro didático de história: entre prescrições e táticas. 2009. 438 f. Tese (Doutorado em Educação) - Universidade Federal de Minas Gerais, Belo Horizonte, 2009.

FONSECA, Selva Guimarães. Caminhos da história ensinada. Campinas: Papirus, 1993. . Didática e prática de ensino de história. 6. ed. Campinas: Papirus, 2007. 
FONSECA, Thais Nivia de Lima e. História \& ensino de História. 2. ed. Belo Horizonte: Autêntica, 2004.

FRANCO, Aléxia Pádua. Apropriação docente dos livros didáticos de História das séries iniciais do ensino fundamental. 2009. $281 \mathrm{f}$. Tese (Doutorado Educação) - Universidade Estadual de Campinas, Campinas, 2009.

FREITAG, Bárbara; COSTA, Wanderly Ferreira da; MOTTA, Valéria Rodrigues. O livro didático em questão. 2. ed. São Paulo: Cortez, 1993.

FREITAS, Itamar et al. A ação do PNLD em Sergipe e a escolha do Livro Didático de História (2005/2007): exame preliminar. In: OLIVEIRA, Margarida Maria Dias de; STAMATTO, Maria Inês Sucupira (Org.). O livro didático de História: políticas educacionais, pesquisas e ensino. Natal: EDUFRN, 2007. p. 53-59.

FREITAS, Itamar. Livro didático de história: definições, representações e prescrições de uso. In: OLIVEIRA, Margarida Maria Dias de; OLIVEIRA, Almir Felix Batista de. Livros didáticos de História: escolhas e utilizações. Natal: EDUFRN, 2009. p. 11-19.

GATTI JÚNIOR, Décio. A escrita escolar da História: livro didático e ensino no Brasil (19701990). Bauru: EDUSC; Uberlândia: EDUFU, 2004.

HÉBRARD, Jean. O autodidatismo exemplar: como Jamerey-Durval aprendeu a ler? In: CHARTIER, Roger (Org.). Práticas de leitura. São Paulo: Estação Liberdade, 1998. p. 35-74.

Três figuras de jovens leitores: alfabetização e escolarização do ponto de vista da história social. In: ABREU, Márcia (Org.). Leitura, história e história da leitura. Campinas: Mercado das Letras; São Paulo: FAPESP, 2002. p. 33-77.

LAJOLO, Marisa. Livro didático: um (quase) manual do usuário. Em Aberto, Brasília, ano 16, n. 69, p. 2-9, jan./mar. 1996.

LUCA, Tania Regina de. Livro didático e estado: explorando possibilidades interpretativas. In: ROCHA, Helenice Aparecida Bastos; REZNIK, Luís; MAGALHÃES, Marcelo de Souza (Org.). A história na escola: autores, livros e leituras. Rio de Janeiro: FGV, 2009. p. 151-172.

MIRANDA, Sonia Regina; LUCA, Tânia Regina de. O livro didático de história hoje: um panorama a partir do PNLD. Revista brasileira de História, São Paulo, v. 24, n. 48, p. 123-144, 2004.

MONTEIRO, Ana Maria. Professores e livros didáticos: narrativas e leituras no ensino de História. In: ROCHA, Helenice Aparecida Bastos; REZNIK, Luís; MAGALHÃES, Marcelo de 
Souza (Org.). A história na escola: autores, livros e leituras. Rio de Janeiro: FGV, 2009. p. 175199.

MUNAKATA, Kazumi. Produzindo livros didáticos e paradidáticos. 1997. 223 f. Tese (Doutorado em História e Filosofia da Educação) - Pontifícia Universidade Católica de São Paulo, São Paulo, 1997.

. Livro didático e formação do professor são incompatíveis? In: CONGRESSO BRASILEIRO DE QUALIDADE NA EDUCAÇÃO: FORMAÇÃO DE PROFESSORES, 2001, Brasília. Anais... Brasília: MEC/SEF, 2002. v. 1. p. 89-94.

_. História que os livros didáticos contam, depois que acabou a ditadura no Brasil. In: FREITAS, Marcos Cezar de (Org.). Historiografia brasileira em perspectiva. São Paulo: Contexto, 2003. p. 271-296.

. O livro didático e o professor: entre a ortodoxia e a apropriação. In: MONTEIRO, Ana Maria; GASPARELLO, Arlette Medeiros; MAGALHÃES, Marcelo de Souza (Org.). Ensino de história: sujeitos, saberes e práticas. Rio de Janeiro: Mauad; FAPERJ, 2007. p. 137-147.

_._._. Livro, livro didático e forma escolar. In: DALBEN, Ângela et al (Org.). Convergências e tensões no campo do trabalho docente. Belo Horizonte: Autêntica, 2010. p. 219-233.

PONDÉ, Glória; ALVES, Nilda; ROLLIN, Wanda. O livro didático na área de comunicação e expressão: algumas idéias. Leitura: teoria \& prática, Porto Alegre, n. 4, p. 26-32, dez. 1984.

SACRISTÁN, José Gimeno. Currículo e diversidade cultural. In: SILVA, Tomaz Tadeu da; MOREIRA, Antonio Flávio (Org.). Territórios contestados: o currículo e os novos mapas políticos e culturais. Petrópolis: Vozes, 1995. p. 82-113.

SILVA, Tomaz Tadeu. O projeto educacional moderno: identidade terminal? In: VEIGANETO, Alfredo (Org.). Crítica pós-estruturalista e educação. Porto Alegre: Sulina, 1995. p. 245260.

TIMBÓ, Isaíde Bandeira. O livro didático de História: um caleidoscópio de escolhas e usos no cotidiano escolar (Ceará, 2007 - 2009). 2009. 273 f. Tese (Doutorado em Educação) Universidade Federal do Rio Grande do Norte, Natal, 2009.

VASCONCELlOS, Maria José Esteves de. Pensamento sistêmico: o novo paradigma da ciência. Campinas: Papirus, 2002. 


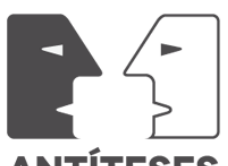

ANTÍTESES

VILLALTA, Luiz Carlos. Concepções do cotidiano no livro didático. In: MARTINS, Angela Maria; ABUD, Kátia; ALBUQUERQUE, Marco Antonio (Org.). Idéias: o tempo e o cotidiano na história. 2. ed. São Paulo: FDE, 1994. p. 39-52.

. O livro didático de história no Brasil: perspectivas de abordagem. Pós-história, Assis, v. 9, p. 39-59, 2001. 